\title{
Jean Paul, lector de Goethe: La edad del pavo como Bildungsroman de transición
}

Fecha de recepción: 19/5/2020. Fecha de aceptación: 20/10/2020.

\section{Resumen}

La edad del pavo (1805), de Jean Paul, puede ser leída como una respuesta al Wilhelm Meister (1795/1796), como la obra de un lector irreverente que oscila entre el homenaje y la parodia. Escrita diez años después de la publicación del Meister, en la novela de Jean Paul se preservan elementos propios de la literatura ilustrada, que reenvían al lector a modelos literarios del pasado, pero estos se mezclan con procedimientos transgresores, que esbozan una nueva forma, muy cercana a las proyecciones schlegelianas acerca de lo que debía ser la novela romántica. El resultado de esta indeterminación es una obra que esboza una estética de la transición, que se verifica también en una serie de motivos literarios ligados al concepto de lo In between. El objetivo de este trabajo es analizar estas imágenes de lo In between para considerar el particular modo en el que Jean Paul se posiciona entre medio de dos grandes tendencias literarias: Ilustración y Romanticismo.

Palabras clave: Bildungsroman; Ilustración; Romanticismo; transición.

Jean Paul, Reader of Goethe: Walt and Vult, or The Twins as a Transitional Novel

\begin{abstract}
Walt and Vult, or The Twins by Jean Paul (1805) can be read as a response to Wilhelm Meister (1795/1796), as the work of an irreverent reader who oscillates between homage and parody. Written ten years after the publication of "The Years of Apprenticeship”, Jean Paul's novel still contains elements of illustrated
\end{abstract}


literature that send the reader back to literary models of the past, but these are mixed with transgressive procedures that outline a new form, very close to Schlegelian projections of what the romantic novel should be. The result of this lack of definition is a hybrid work, in which materials of a heterogeneous nature and belonging to different stages do not manage to merge in a harmonious way. The aim of this work is to analyse the way in which Walt and Vult, or The Twins dialogues with the Goethean Bildungsroman, and what strategies its author uses to express a more ambiguous and obscure vision of Bildung.

Keywords: Bildungsroman; Enlightenment; Romanticism; transition.

\section{Introducción}

Al analizar la cuestión del Bildungsroman, el estudio de Wilhelm Dilthey Vida y poesía (1905) se vuelve una referencia insoslayable. Si bien el responsable de acuñar el término había sido el profesor Karl Morgenstern, fue Dilthey quien lo definió con precisión y sentó las bases para futuros estudios sobre este subgénero. En Vida y poesía, Dilthey dedica un capítulo a las novelas de Johann Paul Friedrich Richter - más conocido como Jean Paul—y las incluye en la tradición del Bildungsroman:

Todas las novelas de Jean Paul versan sobre el mismo tema: son historias de la formación del hombre. Son todas ellas, como tales, continuación del Wilhelm Meister de Goethe, lo mismo que las mejores novelas de nuestros poetas románticos. Esto demuestra que la novela alemana, al llegar a su apogeo, tiene como base común la autobiografía, la profundización psicológica y la historia de la vida anímica. (Dilthey, 2016: 265)

Sin embargo, es necesario establecer varias especificaciones con relación a esta afirmación. Si bien es cierto que la temática de la educación es una constante en la literatura de Jean Paul, en la que pedagogos y maestros adquieren siempre un rol protagónico, no todas sus novelas podrían ser catalogadas como Bildungsromane ni sería correcto considerar "continuaciones del Wilhelm Meister" a textos como Vida del risueño maestrillo Maria Wutz o Siebenkäs, tal como Dilthey sugiere. ${ }^{1}$ Suele considerarse que es en Hesperus (1795), Titan (1800-1803) y, especialmente, en La edad del pavo (1804-1805), donde Jean Paul incursiona en el subgénero de la novela de formación (Koepke, 1991; Swales, 1978). Si las historias de la Bildung representan la iniciación de un joven hasta llegar a la adultez, a través de una serie de aventuras en búsqueda de una identidad propia y, simultáneamente, de una posición en la sociedad (Swales, 1978), estas tres novelas podrían incluirse en el canon del subgénero inaugurado por el Wilhelm Meister.

1 Es el propio Jean Paul quien contradice los postulados de Dilthey. En la segunda edición de su tratado poético Introducción a la estética (1813), el autor de Siebenkäs introduce una clasificación de la narrativa basada en sus propias obras y sostiene que existen tres tipos de novela: la italiana, la holandesa y la alemana. Según Wilhelm Koepke, solo estas novelas alemanas se aproximan al paradigma del Bildungsromany, en este grupo, solo puede incluirse a La edad del pavoy, en menor medida, también a Titan. 
No obstante, el vínculo de estas novelas con el modelo goetheano no deja de ser tan conflictivo como el posicionamiento de su autor en relación con las estéticas imperantes en el particular momento en que desarrolla su obra. Aclamado por el público contemporáneo, pero apartado de los círculos de escritores como los de Weimar o Jena, Jean Paul mantuvo una relación problemática tanto con los jóvenes románticos como con el modelo de los ya consagrados Goethe y Schiller. Estos conflictos para identificar y aceptar a Jean Paul devienen de la naturaleza híbrida de sus novelas, que mezclan y yuxtaponen ideas y motivos de la literatura ilustrada con recursos formales que se aproximan a la estética romántica. ${ }^{2}$ Según Margaret Higonnet, la literatura jeanpauliana posee un enfoque "bifocal" que combina el Clasicismo con el Romanticismo y que, por momentos, se nutre del espíritu didáctico de la Ilustración y, por otros, apela a una sensibilidad crítica compartida con los hermanos Schlegel, Schelling y otros autores románticos (1977: 475). El problema de estudios como el de Higonnet es que, al dejar de lado la relación entre las características formales de la literatura de Jean Paul con su contexto de aparición, se deja entrever que esta naturaleza "bifocal" de las novelas jeanpaulianas es una decisión caprichosa, propia de la escritura de un excéntrico. En contraposición a esto, el análisis de Valeria Castelló-Joubert descubre que las "excentricidades" de las novelas de Jean Paul se justifican exclusivamente por su pertenencia a un período de transición entre la poesía antigua y la poesía romántica (2010: 285).

El objetivo de este trabajo es, entonces, estudiar qué tipos de relaciones de intertextualidad se establecen entre el Wilhelm Meister y La edad del pavo, cuál es la crítica que Jean Paul postula en su obra con respecto al modelo goetheano y de qué modo su novela reformula el modelo de Bildungsroman que había instaurado la obra de Goethe.

Nuestra hipótesis es que Jean Paul mantiene en su novela una postura ambivalente acerca del concepto de Bildung; en ciertas instancias, parece expresar una confianza ilustrada en las posibilidades de la literatura como instrumento de perfeccionamiento del hombre; en otras, adopta una actitud irónica para manifestar una crítica a la idea de progreso. La edad del pavo emplea y a la vez socava las convenciones del subgénero fundado por Goethe, le da a entender a sus lectores constantemente que "no es ni esto, ni tampoco esto otro", o más bien que "es esto y también esto otro". Por ello, consideramos que esta vacilación no es una simple consecuencia del momento histórico en que la producción de Jean Paul se inserta. En La edad del pavo, Richter hace de la transición un modelo estético a partir del uso de imágenes que nos remiten a lo In between, lo indefinido: el batiburrillo, la adolescencia, la casa entre dos condados, y los gemelos dispares, entre otras.

2 Como resultado de esta mezcla, Jean Paul no terminaría de ser aceptado ni por los autores clásicos ni por los románticos. Mientras Schiller y Goethe comentan en su intercambio epistolar su desconcierto ante la aceptación del público de un autor "extraño, como caído de la luna" (cit. en. Fleming, 2005: 17), que perturbaba de un modo extremo las formas clásicas, en el "Fragmento 421", Schlegel lo acusará, en principio, de no ser lo suficientemente romántico (cfr. Schlegel, 2012: 213). 


\section{La edad del pavo y las reflexiones sobre la educación de Jean Paul}

La edad del pavo, de acuerdo con la interpretación de Wilhelm Koepke (1995), es el resultado de la superposición de dos textos entre los que se produce un conflicto irreconciliable, o, para ser más precisos, es el escenario en el que se contrapone una novela ideal con la novela real. Por un lado, nos encontramos con el proyecto de novela de un autor ficcional, apellidado Richter, ${ }^{3}$ que recibe como encargo escribir la biografía de un joven heredero en su paso hasta la vida adulta, mientras se despide del sueño de ser artista, es decir, su propósito es escribir un Bildungsroman. Sin embargo, según sostiene Koepke, el interés de este autor entra en contradicción con las conductas de su personaje principal, que desobedece las intenciones de su biógrafo y se evade en sus sueños de poeta. ${ }^{4}$ Esta situación se complejiza aún más porque, para componer su relato, Richter, que se revela como un autor incompetente, sin demasiadas habilidades para desarrollar su historia, recurre a la estrategia de "plagiar" materiales de la novela que escriben sus propios personajes. Batiburrillo o el Corazón es, a la vez, una obra enmarañada escrita "a cuatro manos", por los mellizos Walt y Vult, que se compone en gran parte de las disquisiciones poéticas, sueños e introspecciones líricas de Walt, el héroe de la novela de Richter.

La edad del pavo se abre con la muerte y lectura del testamento del acaudalado Van der Kabel, a partir de la cual los presuntos herederos se encuentran con la sorpresa de que su pariente ha legado toda su fortuna a un joven desconocido, Walt Harnisch. Este se debate entre la profesión de notario impuesta por el padre y su vocación de poeta. Para cobrar esa herencia, el joven tendrá que cumplir con una serie de requisitos absurdos, que, supuestamente, se orientarían a forjar su formación omnilateral, al forzarlo a dedicarse a tareas vinculadas con oficios absolutamente diversos.

Con este propósito Walt abandona el hogar paterno y, en el camino, recupera a su gemelo perdido, Vult, que había abandonado a su familia hacía tiempo para consagrarse a la música y vivir como un bohemio. Vult pretende ayudar a su hermano a lograr su cometido, pero, además, le propone escribir una novela a dúo. Walt deberá atravesar no solo los obstáculos montados por parientes "desheredados" de Van der Kabel para impedir la obtención de su fortuna, sino también sus propias limitaciones para concentrarse en las tareas de la vida práctica y conectarse con la realidad.

Así, hacia el final de la novela, Walt no está mucho más cerca de lograr su cometido: ha cumplido solo con tres de las dieciséis condiciones impuestas por Van

3 Uno de los recursos más originales de la literatura de Jean Paul es esta inclusión del autor en la propia obra. En La edad del pavo no solo el autor ficcional se llama Richter, sino que también el difunto Van der Kabel se apellidaba originalmente Richter. Por otra parte, los personajes leen y comentan las novelas de Jean Paul Richter. En Siebenkäs y El viaje del rector Florian Fäbel también el autor aparece como narrador o personaje incluido.

4 Podemos concluir, por eso, que la lectura de Koepke también respalda nuestra lectura de La edad del pavo como novela de transición, que media entre un modelo ilustrado (la novela del autor ficcional) y un texto romántico (la novela de los personajes). 
der Kabel, y, además, termina perdiendo a su hermano antes de haber terminado su obra. Es decir que tanto la novela "ficcional" como la novela "real" quedan inconclusas y la formación del personaje, incompleta.

Walt fracasa entonces allí donde Wilhelm Meister triunfa. Cada una de estas novelas expresa una valoración diferente del concepto de Bildung. Si el final del Bildungsroman goetheano reafirma el ideal de su tiempo: que es posible transformar la sociedad para lograr la realización plena de la humanidad a través de la Bildung, La edad del pavo ya no relata la historia de un ideal, sino la de un idealista en el mundo real, material (Cocalis, 1978: 410). Por eso, para Koepke (1991), La edad del pavo usa el modelo del Bildungsroman solo para negarlo.

Sin embargo, al reflexionar sobre la educación de manera teórica, Jean Paul no se separa demasiado del modelo goetheano Bildung. Tan solo un año después de la publicación de La edad del pavo, Richter escribe un tratado teórico sobre pedagogía: Levana (1806) nutriéndose de las mismas fuentes que antes había tomado Goethe para escribir el Wilhelm Meister: el Emilio (1762) de Rousseau y Cartas sobre la educación estética del hombre de Schiller. En Levana también se expresa una confianza en la Bildung como herramienta de perfeccionamiento del hombre: "Querido Dios, cuán infinitamente pequeñas serían mis facultades sin las mejoras del empeño" (1891:38). ${ }^{5}$ La formación es concebida como la adquisición de una experiencia que permita que el alumno arribe a un desarrollo de su personalidad individual y que lo convierta en un ser humano pleno, integro.

Entonces, es posible considerar que el Jean Paul que escribe textos teóricos y el Jean Paul novelista no son idénticos. En La edad del pavo, Richter postula intuitivamente una concepción de la educación más moderna, que advierte la imposibilidad de alcanzar el ideal optimista ilustrado de plenitud y armonía y lo manifiesta a nivel formal.

\section{El batiburrillo y los hermanos: la defensa de una forma no armónica como crítica al racionalismo}

La composición del Wilhelm Meister, como bien señala G. Müller, no es espontánea ni se asimila a la naturaleza, sino que podría compararse a un jardín en el cual el jardinero ha planificado la posición y distribución de cada planta para que pueda florecer (1968:501); por esa razón, Roy Pascal considera que esta novela es un exponente típico del clasicismo alemán (1968: 12). ${ }^{6}$ En la obra de Goethe, la vida se encuentra filtrada por la personalidad armoniosa del narrador que organiza su obra como una unidad. Esta unidad estaría dada principalmente por el héroe, Wilhelm, que constituye el único centro narrativo y foco de atención para el lector (ibíd.: 15).

5 La traducción es nuestra.

6 Es menester aclarar que muchas de las afirmaciones tan categóricas de Pascal acerca de la obra de Goethe han sido relativizadas posteriormente (cfr. Vedda, 2015). 
La edad del pavo, en cambio, no aspira a conformar una unidad armónica, sino que, por el contrario, parece defender una estética de la mezcla. Para componer La edad del pavo, Jean Paul fusiona formas diversas: por momentos parece ser un texto idílico, en otros, una sátira; ciertos pasajes son descripciones oníricas que remedan el estilo de los textos de visiones medievales y algunos capítulos imitan a los relatos de viajes. Como toda obra jeanpauliana, La edad del pavo contiene prólogos pospuestos y epílogos anticipados, la narración se corta repentinamente para incluir cartas del autor ficcional, pasajes de los diarios íntimos de los gemelos o los versos de Walt. Y luego, son los personajes los que se convierten en portavoces de Richter y explican esta "estética del retazo", que se vale de todo tipo de materiales para confeccionar una obra. Al planificar la escritura de su propia novela, Vult sugiere que todo autor se asemeja a un sastre que cose y sutura parches para armar un relato y propone a su hermano que, confeccionar una novela "es cuestión de tomar las historias que escucharon para hilvanarlas y prestarles un adecuado ropaje" (Jean Paul, 1981: 78). Más adelante, los mellizos bautizarían a su obra Hoppelpoppel (traducido como "Batiburrillo"), aludiendo a un platillo que se prepara a partir de un amasijo de ingredientes, de las sobras de otros platos. Asimismo, los juegos de palabras, metáforas barrocas y retruécanos colaboran a crear en La edad del pavo un efecto de "gusto por el caos" (Burello, 2010).

Jean Paul parece llevar a cabo en su novela todas las premisas con las que Friedrich Schlegel caracteriza la novela romántica en Conversación sobre la poesía (1800). En la primera parte de su ensayo, titulada “Épocas del arte poético", Schlegel define la novela con lo que parece, en su idioma original, una tautología: "una novela es un libro romántico” (Schlegel, 2012: 406). ${ }^{7}$ La causa de la predilección schlegeliana por el género novelesco por sobre el drama o la poesía, que habían sido los géneros privilegiados en las poéticas clásicas, es precisamente que la novela carecía de una forma fija y otorgaba a los autores románticos la libertad que estos pretendían para incluir en sus obras elementos heterogéneos. Desde este punto de vista, un libro romántico es aquel que mezcla todos los géneros: "Casi no puedo imaginar una novela sino constituida por una mezcla de narración, canto y otras formas” (ibid.: 410), sostiene Schlegel en Conversación sobre la poesía. Coincidiendo con Schlegel, Jean Paul postula, en su Introducción a la estética, (1804), que lo romántico es lo indefinido, lo "bello indeterminado" que se opone a las nítidas formas clásicas. Si la poesía antigua responde a formas puras, la literatura moderna, sostiene, se caracteriza por la combinación y composición de elementos antagónicos entre sí.

En ese sentido, podríamos considerar que La edad del pavo es, indudablemente, una lectura romántica del Wilhelm Meister y, sin embargo, es posible encontrar otro origen para este uso de la técnica del pastiche: las novelas satíricas del siglo XVIII y, en especial, el Tristram Shandy. En ese sentido, no podemos definir si la estética del revoltijo jeanpauliana es una deuda con la literatura ilustrada de Sterne o un anticipo de la novela romántica; la imagen del batiburrillo reenvía al concepto de literatura de transición, mencionado anteriormente. Por un lado, 
ya en Conversación sobre la poesía, Schlegel cambia su posición condenatoria con respecto a las novelas de Richter ${ }^{8}$ y las incluye en su genealogía de novelas románticas. Pero, por el otro, en Gran Bretaña, es Thomas Carlyle, un cultor de Sterne que escribe su novela Sartor Resartus como un claro homenaje al Tristram Shandy, quien se vuelve un claro defensor de Jean Paul y, finalmente, lo incluye en la tradición de la literatura sterneana.

El autor inglés dedica varios ensayos a la difusión de la obra jeanpauliana entre el público anglosajón y, en ellos, emplea una imagen significativa que permite comparar el estilo del autor de La edad del pavo con el de Wilhelm Meister. Si Müller había relacionado las novelas de Goethe con la imagen del jardín, Carlyle compara las de Jean Paul con una jungla:

Hay pocos autores con los que la reflexión y una cuidadosa desconfianza sobre las primeras impresiones sean más necesarias que con Richter. Él es un fenómeno ya desde la misma superficie: se presenta a sí mismo con una deliberada singularidad: él es un obstáculo para la crítica: para los gramáticos una imperdonabley a veces una insuperable ofensa. No es que sea un ignorante de la gramática o desdeñe las ciencias de la sintaxis, pero las ejerce a ambas con un espíritu latitudinario, se maneja con libertad en el uso de paréntesis, guiones y construcciones subordinadas, inventa cientos de nuevas palabras o altera las viejas, uniéndolas en las más disonantes combinaciones: en resumen, produce oraciones del más heterogéneo, burdo y extraño tipo. Emplea figuras sin límite: ciertamente, el todo es un tejido de metáforas y símiles, alusiones a todas las provincias de la Tierra el Mar y el Aire, entrelazada con cortes epigramáticos, estallidos vehementes o giros sarcásticos, interjecciones, ocurrencias, juegos de palabras je incluso palabrotas! Una perfecta jungla india, parece; un embrollo sin límites, con nada alrededor más que oscuridad, disonancia, jconfusión peor que confundida! (Carlyle, 1885: 15) ${ }^{9}$

Carlyle considera que la forma disonante e inarmónica, por la cual muchos habían cuestionado la calidad de Richter como autor, es deliberada. Teniendo en cuenta la homologación que el autor escocés hace entre literatura jeanpauliana / sterneana, podríamos considerar que, para Carlyle, Jean Paul elabora "batiburrillos" y mezclas estrafalarias para refutar la lógica ilustrada, tal como lo había hecho el creador del Tristram Shandy.

\section{La "edad del pavo" como estado permanente: el tiempo en el Bildungsroman y en La edad del pavo}

El tiempo es un aspecto fundamental en toda caracterización del Bildungsroman. La mayor parte de los estudios canónicos sobre el subgénero emplean criterios ligados a lo temporal para definirlo: Martín Swales sugiere que la novela de formación contrapone dos tipos de tiempo: la simultaneidad (Nebeneinander) o la

8 Ver nota 3. 
temporalidad del corazón, de las posibilidades latentes, y la sucesión (Nacheinander), en la cual, la vida del héroe se desarrolla como una concatenación de experiencias. Esta tensión entre simultaneidad y sucesión es, para Swales, el principio narrativo del Bildungsroman (1978: 29).

Entretanto, Roy Pascal construye su definición a partir de otro concepto ligado al despliegue temporal: la metamorfosis. El Wilhelm Meister se encuentra, según Pascal, centrado en la transformación de Wilhelm en un período determinado de tiempo. Pascal también considera que el Bildungsroman tiene un modo particular y complejo de elaborar la dimensión temporal: los eventos se desarrollan en este tipo de novelas al compás de un tiempo interno y orgánico del héroe, a una velocidad determinada por su propia naturaleza, pero, al mismo tiempo se organizan según el tiempo objetivo y externo (Pascal, 1968: 16).

Por otra parte, la hipótesis de Moretti es que la categoría definitoria del Bildungsroman se vincula con otra arista temporal: la edad del héroe. Moretti sostiene que la juventud es necesaria y suficiente para definir al héroe de este subgénero, dado que, en la modernidad, la juventud es la que carga con todo el sentido de la vida del sujeto, es el período de ruptura, en el cual el hombre comienza a construir su identidad (1987:4).

Podríamos considerar que Jean Paul hubiera coincidido con las tesis de Swales, Pascal y Moretti, puesto que el protagonismo del tiempo en su novela se percibe ya desde el título, que señala un rango etario. También en Los años de aprendizaje de Wilhelm Meister hay una referencia a lo temporal, pero, podemos establecer una diferencia clave entre ambos títulos: Goethe enmarca su novela en "los años de aprendizaje" refiriéndose a un extenso período desde la infancia hasta la adultez; en cambio, al señalar exclusivamente "la edad del pavo", la adolescencia, Jean Paul anuncia que se concentrará en un lapso diferente.

Según postula Martín Koval, las novelas de formación son historias de iniciación y, como tales, se dividen en tres fases bien definidas y delimitadas: la infancia, la adolescencia y la madurez (2018: 23). Entonces, el Bildungsroman de Jean Paul podría ser considerado deficiente, incompleto, al suprimir del relato dos de las tres etapas fundamentales. Al lector de La edad del pavo, puede resultarle llamativo que, al comenzar la historia, su héroe, Walt, acaba de obtener su título como notario y tiene ya veinticuatro años, una edad en la que, evidentemente, la adolescencia de un sujeto, y más aún, en el siglo XIX, ya debería haber terminado, y, sin embargo, se conduce aún como un adolescente. Walt no solo es ingenuo e inexperimentado, sino que sus reacciones emocionales, su forma de afrontar sus obligaciones profesionales, su modo de comprender el amor y entablar las relaciones fraternas y amistosas, son siempre inmaduras. El protagonista de La edad del pavo se encuentra "estancado" en la adolescencia, atrapado en una instancia, sin poder crecer.

Cabría considerar por eso que, si toda novela de formación relata el proceso por el cual el héroe se consolida como adulto y ciudadano a partir de un proceso de 
"negociación" entre sus ideales de juventud y las imposiciones de la sociedad cuyo final implica siempre una renuncia (Koval, 2018), resulta discutible que la novela de Walt pertenezca a dicho género.

En todos los oficios en los que debe desempeñarse para cumplir los requisitos del testamento de Van der Kabel, Walt comete errores. Ya sea confeccionando documentos o restaurando pianos, Walt no es eficiente en ninguno y esto, según deja en evidencia el relato, no se debe a una "incapacidad natural" sino a que el joven no asume el trabajo con una actitud adulta ni se compromete con las tareas que le han asignado: mientras afina pianos observa a las señoritas de las casas en las que trabaja, cuando elabora actas notariales imagina versos nuevos o se evade en sus ensoñaciones.

Walt es incapaz de madurar porque le falta esa capacidad de renuncia que Wilhelm sí poseía. Luego de un paso frustrado por el teatro, Wilhelm decide abandonar la actuación para sumarse a la Sociedad de la torre; Walt, en cambio, se resiste tajantemente a abandonar la poesía y reafirma constantemente su rol como compositor de "versos estirados", un género que él mismo había creado. El rechazo activo que el héroe jeanpauleano siente por el mundo de la prosa y por aquellos que reniegan de su vocación se tematiza en varias escenas. En cierto momento, Walt acude a una posada con uno de los familiares "desheredados" de Van der Kabel, el pasante Knoll, que es caracterizado como la encarnación del filisteísmo burgués. Para Knoll, resulta evidente que la labor de artista es un buen pasatiempo, pero nadie debería consagrarse a ella prolongadamente. Por eso, conmina a Walt a abandonar la poesía, si es que quiere progresar; lo mismo había sugerido su padre, e, incluso, su maestro, pero Walt resiste y reacciona, por única vez en todo el relato, con ira. El narrador comenta que, tras la insistencia de Knoll:

El dulce Walt, digo, como un león atacado, se lanzó sobre el pasante y le asió de los hombros con ambas manos, gritando con tal fuerza desde lo hondo de su atormentado pecho, que aquél dio un brinco, temiendo un golpe mortal: -Pasante, vive Dios, yo procuraré ser un buen jurista, de intachable conducta, en atención a mis pobres padres. Pero digo también, pasante: que un meteorito parta en dos mi corazón, que el Dios eterno me entregue al más furioso de los diablos si abandono el verso estirado y el sublime arte poético. Luego miró a su alrededor y dijo en tono solemne: -Yo seguiré creando. (Jean Paul, 1981: 70)

Esta declaración no dista de lo que podría haber respondido Wilhelm a Werner al principio de su recorrido, cuando este le sugería que abandonase el teatro. La diferencia entre ambos protagonistas radica en que Wilhelm es capaz de modificar sus convicciones a través de la experiencia, puede aprender de sus fracasos. Inversamente, Walt fracasa una y otra vez y no desiste. De hecho, junto a su hermano envía en reiteradas oportunidades su novela para ser publicada y, a pesar de los constantes rechazos, no consigue dimitir.

En Vocación y renuncia (2018), Koval distingue como otro de los signos de maduración del héroe el hecho de forjar una pareja estable y proyectar una familia. Es 
así como Wilhelm termina de formarse cuando se involucra en la educación de su hijo Felix y se casa con Nathalie. Walt no conseguirá realizarse en el aspecto amoroso tampoco, el joven se enamora de Wina, la hija de un general llamado Zablocki, que lo contrata como notario para copiar sus cartas eróticas. Esto último constituye una sutil ironía por parte del autor: mientras el joven héroe copia las cartas eróticas del viejo capitán, el erotismo no ocupa ningún lugar su vida. Contrastando con Wilhelm, que incluso antes de establecerse con Nathalie, tiene una vida sexual madura, cuyo resultado manifiesto es Felix, Walt se comporta a nivel sexual como un niño, no hay ninguna señal en el relato de que imagine junto a Wina algo más que un amor platónico, porque sistemáticamente traslada todo al ámbito ideal. Para referirse a su amada, Walt emplea apelativos como "santa virgen", "monja de Dios" o "hermana espiritual superior".

Más aún, resulta improbable que su historia de amor pueda concretarse en algún momento, no solo porque al comienzo de la historia Wina está comprometida, sino porque, aun luego de la ruptura de ese compromiso, no era factible que la antigua novia de un conde e hija de un general pudiera casarse con un sujeto sin fortuna ni demasiadas perspectivas de obtener una posición en el futuro. Así, Walt queda en sentido amoroso también como un personaje trunco, que no puede desarrollarse, ni proyectarse a futuro.

De hecho, la noción de 'futuridad' no forma parte del imaginario de Walt; él ama a Wina porque recuerda que esta muchacha lo había visitado durante una enfermedad cuando ambos eran niños. Gran parte de las ensoñaciones de Walt son, en realidad, flashbacks en los que el poeta recuerda su infancia y el hogar familiar - siempre apelando al tono del idilio-; una actitud que, nuevamente, implica una confrontación con el Wilhelm Meister.

Una de las razones por las que el héroe goetheano logra madurar y puede atravesar diferentes etapas, es su capacidad de olvido. Wilhelm supera el trauma de haber abandonado injustamente a Marianne, su primera amada y en sueños se despide de ella; solo después de esto se encuentra con la mujer que sería su esposa, Nathalie. Walt es diferente, se aferra al pasado y demuestra siempre una nostalgia por lo infantil.

Así, podemos ver en la dupla Wilhelm Meister /La edad del pavo una confrontación entre los dos modelos de novela que Moretti distingue: las novelas de transformación y las de clasificación (1987: 7). El Bildungsroman de Goethe es un relato de clasificación porque, a pesar de centrarse en la juventud, la concibe como un período de la vida supeditado a la madurez, limitado. Las novelas de transformación, en cambio -el ejemplo que Moretti otorga es La educación sentimental de Flaubert, pero bien podría incluirse La edad del pavo en este grupo-se dedican a personajes que se resisten a madurar, que ven al crecimiento como una traición.

Esto es exactamente lo que le sucede a Walt; quien nunca logra el equilibrio entre los tiempos externo e interno que, como se ha afirmado anteriormente, constituye uno de los rasgos esenciales del Bildungsroman. El joven poeta permanece 
siempre en el presente puro, en la simultaneidad de la imaginación poética; él se repliega en su tiempo interno y eso impide que avance, que progrese. Este es un hecho que cabe destacar, Jean Paul no solo confronta con la generación que lo precede, por medio de la figura de Walt, elabora también una solapada crítica a sus contemporáneos, los poetas románticos. Publicada tan solo tres años después de la aparición de Enrique de Ofterdingen (Novalis, 1802), La edad del pavo advierte, desde una posición que, en este aspecto es ilustrada, los peligros que suponen la evasión y el solipsismo del poeta romántico que, como Heinrich, le da la espalda a la realidad para replegarse en su interioridad (Fleming, 2005). De acuerdo con la lectura de Fleming, esto motiva que el autor elabore una perspectiva distanciada con su personaje principal y, en cambio, construya una mayor complicidad con Vult, el hermano satírico y realista, que sería, para Fleming, el auténtico héroe de la historia.

No obstante, la representación del tiempo es otro de los aspectos en los que la tendencia ilustrada y la romántica se superponen en la novela de Jean Paul, porque, si bien se critica la actitud "inmadura" del poeta romántico, el tiempo se representa "románticamente". El hecho de que Walt no logre completar ninguna de las tareas que se le asignan y que siempre aplace el momento de cumplir con sus obligaciones terrenales tiene un correlato formal en la novela; es posible afirmar que, en La edad del pavo, Jean Paul emplea una estética de la postergación: constantemente, el autor ficcional incrusta en el texto episodios, anécdotas, recuerdos, sueños, o cualquier otro elemento que podría catalogarse como digresión. El biógrafo de Walt promete a sus lectores que les contará un suceso importante en la vida del héroe, pero luego se concentra en un detalle, que suscita en él una disquisición teórica o evoca un recuerdo, que, a la vez, hace surgir otro relato. De esta forma, la novela parece estar organizada con una lógica azarosa, caprichosamente, a partir de lo que, de manera espontánea, surge en la mente del autor.

El azar es el leitmotiv de La edad del pavo; la cuestión de la contingencia es abordada en varios episodios de la novela. Uno de ellos es el capítulo dedicado a narrar la salida de Walt de su pueblo hacia la ciudad, en búsqueda de la herencia, momento en el que realiza su primera cabalgata. El autor aclara entonces que, si su héroe nunca había montado un caballo, él tampoco había escrito sobre cabalgatas, haciendo surgir nuevamente la cuestión de la impericia. Jean Paul pretende hacer manifiesto que ni él ni su personaje van a llegar nunca a la "maestría":

En la montura, Walt tuvo que trabajar lo suyo, como autodidacto que era, para sentarse derecho y acomodarse en la silla, llevar las manos a las bridas, colocar los faldones de la levita sobre los lomos, ajustar las botas en los estribos e iniciar la partida. Al final, el sesudo rocín no quiso caminar. Los delicados toques de Walt, con la fusta, al lomo eran tanto como si le atizara con una crin de caballo. Unos cuantos manotazos maternales los acogió como verdaderas caricias. Por fin, el padre jurista blandió el bieldo y le propinó en las nalgas, con el mango, un suave espaldarazo, para así lanzar a su hijo, como caballero, de la aldea al mundo: al mundo docto y al mundo bello. Aquello fue para el caballo una señal para desplazarse hasta el riachuelo; aquí se detuvo ante la imagen del jinete 
reflejada en el espejo del agua. Bebió de ésta, y mientras el notario bregaba con violentos movimientos de pies y estribos, pues media aldea se le estaba burlando, y el hostelero con ellos, el trotón pareció percatarse de su error al detenerse, y recondujo a Walt del abrevadero a la puerta del establo, contrariando bastante las intenciones del jinete. -Espera —dijo el padre, corriendo hacia la casa. Volvió de nuevo y le alargó una bolita. —Ponle esto en la oreja —dijo-; es para darle seguridad. Así marchará, pues el plomo tiene que enfriar al animal, pienso yo. El corcel, como una pieza de artillería, la cabeza lanzada hacia el portal y la oreja cargada con el balín, salió disparado, y el notario atravesó raudo la aldea expectante, sentado en la montura, al primer ensayo, como una coma torcida, tras escuchar las últimas palabras del pasante deseándole suerte. - Ya está exclamó Lukas, y fue a emparvar la hierba. (Jean Paul, 1981: 78)

El pasaje anterior grafica varios de los aspectos que venimos explicando con relación al tiempo: en primer lugar, resulta curioso que, en principio, Walt no logre "arrancar" la marcha y es el padre quien debe darle un empujón al caballo; aun así, no puede hacer avanzar el caballo. Más adelante, el padre vuelve a intervenir colocando unas bolitas en las orejas del rocín para que corra, pero, entonces, Walt ya no puede dominar al animal y pierde los estribos. La metáfora es clara: Walt es un héroe que ni puede tener el control, ni logra tomar las riendas de su vida, ni decidir nada. Todo lo que le sucede al joven poeta depende del azar, lo cual vuelve a erosionar la clasificación de Laedad del pavo como Bildungsroman. Es más, esto incluso rebate la noción de Bildung, tan cara a la filosofía ilustrada, dado que, si el mundo se rigiera por el azar y fuesen ciertas las palabras de Walt: "todos somos juguetes del destino", entonces, la Bildung, sustentada en el ideal burgués del sujeto que se construye a sí mismo y aspira encontrar métodos para perfeccionarse, no podría existir.

Justamente por eso, Dilthey censura duramente la estética jeanpauliana, citando los mismos motivos por los cuales Carlyle la elogiaría en su ensayo:

\begin{abstract}
En la vida de este genial hombre imaginativo quedan totalmente relegadas a segundo término la inteligencia que comprende y explica con arreglo a las relaciones causales, la voluntad racional que ordena los fines claros dentro de un sistema de medios enlazados en conexión causal y, por tanto, la energía intelectiva que modela la vida y plasma el carácter, es decir, las fuerzas por medio de las cuales domeñaba Goethe lo que en él había de demoniaco y a las que Schiller recurría para organizar y regular su vida. (Dilthey, 2016: 256)
\end{abstract}

Para Dilthey, Jean Paul es inferior a Goethe porque, a causa de esta disposición azarosa de los materiales, no logra encontrar y explicar las conexiones causales entre los hechos. Sin embargo, consideramos que esta "falta" no responde a la incompetencia del autor, sino que está deliberadamente pergeñada: Richter busca discutir la conexión racional entre un hecho y otro, quiere cuestionar que los eventos se sucedan unos a los otros siguiendo una causalidad lógica, motivados por alguna razón. Aquí, conviene volver a mencionar las conclusiones de Moretti, que sostiene que el Bildungsroman cuenta con una estructura teleológica, es decir, que el significado de cada suceso individual se explica en la resolución de la historia (1987: 7). En este tipo de novelas es el encadenamiento, el orden diacrónico el que le da sentido a cada episodio, el Bildungsroman o "la novela de transformación", según la denominación de Moretti, es un género que persigue un orden. 
No es posible encuadrar a La edad del pavo en esta caracterización; la novela de Jean Paul no parece orientarse de acuerdo con un destino prefijado desde un principio, ni obedecer algún tipo de planificación. Los propios personajes de Jean Paul parecen explicar este rasgo: cuando Walt decide viajar, lo hace sin consultar ninguna guía; lo que el joven desea es vagar sin ningún tipo de meta fija. Walt incluso lo expresa manifiestamente y confiesa que "le gustaba marchar dando rodeos" (Jean Paul, 1981: 134).

"Marchar dando rodeos" es también una metáfora de la estructura de la novela de Richter: mediante las digresiones, postergaciones e incrustaciones azarosas de episodios, se destruye la estructura lineal y cronológica del Bildungsroman. La historia de Walt y Vult adquiere la traza de un arabesco, la forma a la que toda obra romántica debía aspirar, por su carácter intricado e infinito (Schlegel, 2012). La edad del pavo es una novela potencialmente infinita: al no perseguir ningún rumbo fijo y otorgarle al narrador la libertad de añadir todo aquello que acudiese a su mente, la historia podría continuarse ad eternum.

Kommerell (1977) encuentra una explicación filosófica a la ruptura de la linealidad en La edad del pavo. El crítico afirma que el hecho de que la experiencia de Walt y Vult no pueda graficarse con una línea ascendente constituye una crítica a la noción ilustrada del progreso. Ya no es solo que Walt no pueda aprender, sino que La edad del pavo pone en entredicho la confianza en que la posibilidad de perfeccionamiento sea inherente al hombre, o, al menos, que el hombre avance de manera constante hacia la superación. Esta postura de Kommerell encuentra sustento en las palabras del propio Richter en Levana: "Porque el hombre no está formado para crecer enteramente hacia arriba, como las plantas y los cuernos de los ciervos; ni tampoco hacia abajo, como las plumas y los dientes; sino como los músculos, hacia ambos extremos a la vez" (Jean Paul, 1891: 109). Se percibe en esta cita -y en toda la literatura jeanpauliana- una perspectiva mucho menos optimista con respecto al potencial de la educación estética y la Bildung que en Schiller y Goethe. Este desencanto con respecto a los avances de la modernidad ha sido frecuentemente vinculado con la crítica romántica a lo moderno. ${ }^{10}$

Empero, esta lectura en clave romántica de la estructura formal de La edad del pavo podría confrontarse con otra interpretación en clave ilustrada, que relaciona la naturaleza digresiva y azarosa de la obra de Richter con el pensamiento de John Locke y su teoría asociacionista, a la que Richter habría arribado a través de la lectura del Tristram Shandy (Higonnet, 1977). Así, la representación del tiempo también reproduce esta yuxtaposición de premisas ilustradas y románticas con la que pretendemos definir la literatura jeanpauliana.

10 Algunos incluso han tildado a Richter de nihilista. En tal sentido, existe una recopilación de sus textos más escépticos a la que se la ha titulado "El alba del nihilismo" que incluye el famoso relato onírico "Discurso de Cristo muerto desde lo alto del cosmos diciendo que no hay Dios". 


\title{
5. Una casa entre dos localidades, una posada sin muros y un par de mellizos dispares: la ironía romántica como expresión del desgarramiento del sujeto
}

Los héroes del Bildungsroman suelen ser sujetos corrientes, promedio, sin ningún rasgo particular que los destaque. Este no es el caso de Walt; Walt es un joven extraordinario, no solo porque su carácter sea fuera de lo común sino porque las circunstancias que lo rodean, ya desde su nacimiento, son excepcionales. Los gemelos Walt y Vult, hijos del alcalde de Elterlein, nacen en un escenario muy poco convencional, que el autor ficcional explica detalladamente:

\begin{abstract}
Elterlein tenía dos amos: al lado derecho del riachuelo se situaban los vasallos del Príncipe y al lado izquierdo los colonos del gentilhombre o caballero; en lenguaje llano se llamaban unos a otros, incorrectamente, los derechos y los izquierdos. Ahora bien, según todos los libros catastrales y de litigios fronterizos, en tiempos antiguos la línea de demarcación, que era el riachuelo, pasaba cerca de la casa del alcalde. Posteriormente, el riachuelo cambió de cauce, o acaso un tórrido verano evaporó sus aguas; el caso es que la vivienda resultó biseccionada, de suerte que en su tejado- e incluso su cielo raso, y hasta el pequeño sofá cuando alguien se sentaba en él- se levantaba sobre dos territorios. Y así se convirtió esta casa del viejo alcalde en punto clave, jurídico y económico al mismo tiempo. Con frecuencia, Lukas paseaba sus ojos, [...] recordando que por la noche sería "derecho" - pues dormía en la zona del príncipe- y solo de día era "izquierdo", ya que la mesa y la estufa caían sobre el territorio noble. (Jean Paul, 1981: 41)
\end{abstract}

Si la novela de formación, como género racionalista, otorga preponderancia a los límites, a la definición clara de espacios y estructuras, en La edad del pavo, hallamos numerosas imágenes de espacios con límites difusos, en los que se entremezclan elementos disimiles. Tras abandonar el hogar familiar, los mellizos se reencuentran en una posada, también singular, y se alojan en una habitación sin un muro, o más bien, con un muro hecho pedazos, en la que se pierde la separación entre la construcción humana y la naturaleza. Estos constantes intentos jeanpaulianos por unificar polos antitéticos han sido leídos como ejemplos de la ironía romántica.

Para el romanticismo, la ironía es el recurso que posibilita la unión de contrarios, puesto que implica la presencia simultánea de pares antagónicos. Este movimiento artístico, que nace en gran parte como reacción a la modernidad y como toma de consciencia de la escisión del sujeto en el mundo moderno, concebirá a la poesía como el único camino para recuperar esa unidad perdida: "La poesía hermana y une con lazos indisolubles a todos los espíritus que aman" (Schlegel, 2012: 33), se sostiene en Conversación sobre la poesía.

La ironía oculta la ambición utópica de reunir lo que se desunió y acabar con la fragmentación de la modernidad para volver a formar sujetos no alienados. Sin embargo, el irónico es consciente del carácter utópico, sin posibilidad de existencia, de sus deseos, de lo cual deviene un humor amargo. En La edad del pavo, esta risa que se mezcla siempre con un dejo de tristeza aparece constantemente: 
cada vez que nos encontramos con una situación que parece humorística o hasta grotesca esta se corta abruptamente con una reflexión nostálgica, pero también sucede a la inversa, cuando el relato se vuelve sumamente poético, el narrador introduce repentinamente un incidente cómico que corta con lo sublime. En la literatura de Richter, la risa y la lágrima son dos caras de una misma moneda. Es el propio Heine quien advierte sobre Jean Paul: "el sentimentalismo lo domina siempre, y su risa se transforma de repente en llanto” (Heine, 2007: 161).

Empero, ninguna construcción de La edad del pavo reúne tan bien los opuestos ni resulta tan irónica como la de la pareja de hermanos que la protagonizan. Jean Paul es el responsable de bautizar a una de las figuras más fecundas de la literatura alemana, el Doppelgänger o doble. En gran parte de su obra, es posible hallar pares de caracteres que, más que dos individuos, conforman las partes fragmentadas de un yo que, de reunirse, formarían un sujeto total y armónico ${ }^{11}$. Walt y Vult ${ }^{12}$ son una pareja irónica: mientras Walt representa el espíritu lírico y encarna el prototipo de poeta sentimental, Vult es un autor satírico, ligado al mundo terrenal. Esta oposición entre los mellizos está presente desde la primera descripción que se hace de ambos al nacer:

Pronto se vio que en un futuro la vida intelectual iba a ser la especialidad de Gottwalt. Predilecciones paternas aparte, saltaba a la vista su figura de bucles de oro, brazos delgados y busto grácil[...]Además, el niño estaba dotado de un temperamento dócil, pudoroso, delicado, piadoso, sensible y soñador[ ...] Del gemelo más joven, Vult, se decía en cambio, con cierto humor, que el fornido, rapaz, de negro cabello y picado de viruelas que se peleaba con media aldea, siempre vagabundo como auténtico y ambulante thêatre aux Italiens, capaz de imitar todas las fisionomías y voces era otro tipo: a éste dadle unas actas o el expediente bajo el brazo o una silla tabernera bajo el culo. (Jean Paul, 1981: 43)

Luego, la antítesis se hace aún más gráfica cuando cada uno de los dos hermanos es destinado profesionalmente a los polos opuestos cielo/ tierra; mientras que Walt cuenta con una "escalera celestial" como futuro párroco, Vult tendría que ensuciarse con "la tierra de las leyes" (id.). Walt y Vult parecen compartir una misma postura estética con Jean Paul y por eso creen que reuniendo sus individualidades lograrían una obra de arte perfecta:

¿Qué puedo hacer? Yo solo, nada; pero contigo, mucho: una obra. Una pareja de gemelos debe engendrar, como su propio trasunto, un hijo, un libro, una espléndida novela al alimón. En ella yo río y tú lloras, o vuelas. Tú eres el evangelista, y yo el animal que está detrás de él; el uno mueve al otro. En ella se conjugan los pares opuestos: hombre y mujer, casa y establo, yo y tú. (ibíd.: 98)

Puesto que los hermanos son también escritores y su historia es la historia de la composición de una novela cuyo contenido, además, coincide exactamente

11 La historia de Siebenkäs, por ejemplo, se centra en dos amigos inseparables que intercambian sus nombres, de modo que cada uno asume la identidad del otro, con todas las complicaciones que esto implica. 
con el de la novela creada por Richter, el biógrafo por encargo, La edad del pavo se satura con especulaciones teóricas acerca de la forma "novela", el estatuto de la literatura o su función social. Entonces, la difuminación de los bordes encarnada en las metáforas de la casa entre dos condados o la habitación sin un muro se manifiesta también en relación con los planos narrativos. Relato y reflexión metaliteraria se entremezclan en la estructura del texto, un argumento más para vincular la novela de Jean Paul con la poética de Schlegel.

Tanto en sus ensayos como en los fragmentos, Schlegel postula la necesidad de romper la división marcada entre la poesía y la reflexión teórica y promueve la aparición de una literatura autorreferencial, que reflexione sobre sí misma. Son varios los pasajes de Conversación sobre poesía en los que señala el imperativo de que todos los discursos, incluso el científico, confluyan en el discurso poético. En primer lugar, se explica que la obra de arte romántica deberá volverse irónica, es decir, deberá contener su propia crítica. En segundo lugar, la crítica literaria tendrá que constituir un arte:

La poesía solo puede ser criticada por la poesía. Un juicio sobre el arte que no sea él mismo una obra de arte está o bien en la materia como presentación de la impresión necesaria en su devenir o a través de una forma bella y un tono liberal en el espíritu de la antigua sátira romana no tiene ningún derecho en el reino del arte. (Schlegel, 2012: 129)

La teoría de la novela jeanpauliana no dista demasiado de la de Schlegel. En su Introducción a la estética, Jean Paul incluye varias sentencias que bien podrían haber sido recortadas de alguno de los ensayos del autor de Lucinde:

\begin{abstract}
El poeta, pues, debería de serle posible, englobar en sí todas las ciencias, es decir, todas las unilateralidades: entonces se convierte él en multilateralidad, porque el poeta es la única persona con vocación y fuerza para captar las unilateralidades desde un único punto de vista y conciliarlas a nivel más alto, pudiendo verlo todo panorámicamente, en ágil perspectiva. (Jean Paul, 1991: 80)
\end{abstract}

Luego, ya en su novela, Richter propondrá que los propios escritores, para salvarse de los "malos críticos", formen a un "crítico ideal" que sea también poeta y, al explicar el método didáctico que se emplearía en el aprendizaje del crítico, recomienda la lectura exclusiva del Wilhelm Meister. De este modo, Jean Paul establece un vínculo dicotómico, e inclusive irónico, con la obra de Goethe: primero propone que, para entender su novela, hay que leer a Goethe y se construye como su heredero, pero tan solo unas oraciones más tarde los lectores se enteran de que el nuevo crítico formado según su método termina pronosticando que, en un lapso de cinco años, Goethe estaría tan postergado como entonces ya lo estaba Wieland.

Los sentimientos oscilantes entre el amor y el odio de La edad del pavo hacia el Wilhelm Meister se traducen en episodios que reescriben paródicamente motivos de la novela de Goethe. Jean Paul parodia la amistad entre el burgués Wilhelm y el noble Lotario en el relato de la fallida amistad de Walt con el conde Kothlar. 
En la novela de Goethe, la amistad es una de las bases en las que se sustentaría la comunidad utópica proyectada por la Sociedad de la torre. La propuesta goetheana es que la sociedad perfecta nace de la unión entre aristocracia y burguesía. Por su parte, Walt intenta tener un amigo noble, al igual que Wilhelm, pero Jean Paul enfrenta a su personaje con la realidad. En su mundo interno, Walt desarrolla un amor desmedido por Kothlar y, desatento a las señales del afuera, se convence de que él y el conde son amigos; el aspirante a poeta nunca percibe que el suyo es un amor no correspondido, que su supuesto amigo lo ignora y ni siquiera recuerda su rostro. Walt tampoco advierte el rechazo de Kothlar cuando Vult le propone que, para ser aceptado, visite a Kothlar disfrazado de aristócrata. Solo cuando este descubre la estratagema de Walt y lo expulsa de su casa, el joven consigue enfrentar los hechos (cfr. Jean Paul, 1981: 229-233). Jean Paul indica que la amistad entre aristocracia y burguesía es un imposible, su postura es escéptica con respecto a otra de las premisas ilustradas: el ideal de fraternidad e igualdad entre las clases sociales.

Otro de los motivos del Wilhelm Meister con los que La edad del pavo ironiza es el de la Sociedad de la torre: en la novela de Goethe, esta sociedad secreta era la responsable de prefigurar el destino del héroe. Aquí, Vult, a modo de la Sociedad de la torre, intenta anticiparse a los pasos de su hermano en el viaje que este había emprendido, según creía él, en soledad. Vult no solo supervisa, sino que actúa como un demiurgo que planifica los caminos que luego Walt escogerá. Así, en primer lugar, en una posada, Walt se sorprende cuando el posadero sabe su nombre antes de que presentarse; luego, lo descubre por escrito al llegar a otro hospedaje. En el camino, el héroe se encuentra con el cuadro del artista callejero que representaba los eventos que habían sucedido en su viaje: en la obra aparecen los rostros de los gemelos y la frase que dio nombre a su hermano "Quos Deus Vult”. Las duplicaciones irónicas no cesan allí: Vult también envía a su mellizo una carta en la que "adivina" su itinerario, tal como lo hacían los registros escritos de la Sociedad de la torre.

De hecho, esta nueva alianza entre los hermanos, reunidos tras una larga separación, podría ser considerada una comunidad utópica a la manera de la Sociedad de la torre, aunque reducida a escasos dos integrantes. Vult le propone a Walt, después de que este regresara del viaje, vivir juntos y compartir "como una pareja de avecillas, un mismo nido" (Jean Paul, 1981: 414). Los hermanos imaginan que pasarán una temporada escribiendo Batiburrillo día y noche, y que el pequeño cuarto compartido sería un oasis de creatividad constante: "los dos escribiremos y crearemos hasta echar humo. Viviremos solo para los libros y los manuscritos" (id.). Sin embargo, esta comunidad sustentada por el amor fraternal finalmente se desbarata: Vult no tolera la docilidad y la falta de pragmatismo de Walt, Walt se siente a menudo herido por la agresividad de Vult.

Sumado a estas diferencias triviales existe una causa de mayor profundidad que desgasta el lazo entre los mellizos: el carácter solipsista de Walt -que de los dos hermanos es el que siempre está más dispuesto a expresar su amor fraterno- como así también su tendencia a recluirse en su mundo interno, 
lo vuelven incapaz de observar el mundo exterior y, por ende, de atender los sentimientos de los otros. El poeta no detecta que Vult se ha enamorado también de Wina y alardea de sus avances amorosos con la hija del capitán delante suyo, sin advertir que está lastimando a su hermano. Jean Paul revela que, de personajes egoístas, individualistas, como Walt (y gran parte de los héroes de las novelas de formación), no podrá nacer una sociedad utópica. Finalmente, Vult abandona el "nido" compartido dejando una carta; Walt escucha el sonido de la flauta de su hermano alejándose, pero no logra darse cuenta de que su hermano lo está abandonando.

"Te dejo como eras y me voy como vine [...] tu no vas a cambiar ni yo a mejorar" (Jean Paul, 1981:503), reconoce Vult al despedirse de Walt. Es a raíz de esta frase final que, para autores como Wulf Koepke (1991), no podemos decir que La edad del pavo sea un Bildungsroman, simplemente, porque no hay ninguna Bildung hacia el final; ninguno de los dos hermanos se transformó; todo sigue igual que al principio. Richter emplea, desde esta perspectiva, el formato del Bildungsroman y realiza en su novela "guiños" al género, pero solo para terminar socavándolo. La edad del pavo se cierra, para Koepke, con un gesto de amarga ironía con respecto al potencial de la Bildung.

Empero, la postura de Koepke puede contrastarse con lecturas como la de Fleming, que nos recuerda que, en la literatura de Jean Paul, la amargura y el escepticismo nunca son absolutos. Fleming considera que el humor jeanpauliano es una toma de distancia respecto a la escuela romántica (2005: 126). Gracias al humorismo, en La edad del pavo, se establece un vínculo entre la poesía, lo artístico y el mundo material. De este modo, según Fleming, Jean Paul plantea una salida a las formas más solipsistas de la metafísica poética del romanticismo, al tiempo que se enlaza con la literatura burguesa y realista. Esta elucidación es relevante en nuestro trabajo porque nos permite reafirmar nuestra interpretación de la literatura de Jean Paul como una literatura de transición. La veta cómica, encarnada por Vult dentro de La edad del pavo, se inscribe en el humor satírico propio de la Ilustración. Como buen satírico, Vult persigue siempre una intención didáctica; pretende, sin demasiado éxito, corregir los defectos de su hermano.

Del mismo modo se comportan las estructuras metatextuales; si bien es cierto que la mayor parte de ellas aluden irónicamente a la cuestión de la literatura, algunas tienen una manifiesta intención didáctica y hasta moralizante. Jean Paul declara en una de sus intervenciones que el objetivo de su novela es enseñar y, efectivamente, el didactismo surge en La edad del pavo de un modo mucho más directo que en la novela de Goethe. En algunos pasajes, Richter se coloca en el rol de un docente que alecciona a sus discípulos y emplea un tono moralizante similar al de los autores de novelas sentimentales como Richardson. En ese sentido, no sería acertado afirmar que Jean Paul rechaza activamente el ideal ilustrado de la Bildung, sino más bien que esta y otras de las firmes convicciones de la generación anterior son observadas, en ciertos pasajes, con desconfianza. 


\section{Conclusión}

En La edad del pavo, la novela de su apogeo como autor, Jean Paul se anima a reflexionar acerca del vínculo entre su literatura y la de los autores de la época de Goethe; así, elabora un texto que dialoga constantemente con el Wilhelm Meister.

Suele considerarse que la literatura de Jean Paul es extravagante, e incluso grotesca, por su mezcla constante de elementos disímiles que no logran conciliarse; se afirma que "fracasa" en el intento de realizar una síntesis. No obstante, consideramos que esta "impericia" del autor interno, es una estrategia deliberadamente construida por el autor real, siguiendo la misma lógica de Sterne, en su creación de la figura de Tristram como un narrador poco fiable.

En nuestra investigación, hemos comprobado que la no armonización de opuestos, la imposibilidad de definirse entre un extremo y otro que se observa en novelas como La edad del pavo no son solo una consecuencia del particular momento de transición entre Ilustración y Romanticismo en el que Richter se consolida como escritor. También responden a la decisión estética de un autor que resuelve no adherir plenamente a ninguna de las tendencias de su época.

Las imágenes de lo In between, como el batiburrillo, la casa entre dos condados o los mellizos dispares son la manera en que Jean Paul manifiesta esta decisión de posicionarse como autor de transición en términos estéticos y, por eso, cumplen un rol fundamental en la novela. 


\section{Bibliografía}

"Benham, G. (1978). On Some Salient Features of Jean Paul's Pedagogical Writings. En Colloquia Germanica, vol. 11, núm. 3, pp. 233-262.

" Burello, M. (2008). La 'edad del pavo' de la literatura. A propósito de La edad del pavo, de Jean Paul. En: Revista de Filología Alemana, vol. 16, pp. 65-85.

"Carlyle, T. (1885). Jean Paul Richter. En Critical and Miscellaneous Essays, pp. 4-27. Nueva York: John B. Alden.

"Castelló-Joubert, V. (2010). Jean Paul y La edad del pavo. Una teoría de la novela. En De la ilustración al romanticismo, J. L Rearte y M. J. Solé (eds.). Buenos Aires: Prometeo.

"Cocalis, S. (1978). The Transformation of "Bildung" from an Image to an Ideal. En Monatshefte, vol. 70, núm. 4, pp. 399-414.

" Dilthey, W. (2016). Vida y poesía. Trad. de. W. Roces. México: FCE.

"Fleming, P. (2005). The Pleasures of Abandonment. Jean Paul and the Life of Humour. Würzburg: Königshausen \& Neumann.

" Heine, H. (2007). La escuela romántica. Trad. e introd. de R. Setton. Buenos Aires: Biblos.

" Higonnet, M. (1977). Jean Paul Richter: "Kunstrichter". En: The Journal of English and Germanic Philology, vol. 76, núm. 4, pp. 471-490.

" Jean Paul (1991). Introducción a la Estética. Ed. de Pedro Aullón de Haro sobre la versión de Julián de Vargas. Madrid: Verbum.

" Jean Paul (1981). La edad del pavo. Trad. de M. Olasagasti. Madrid: Alianza.

" Jean Paul (1891). Levana or The Doctrine of Education. Londres: George Bell and Sons.

" Koepke, W. (1995). Narcissus and the Poet: Jean Paul's Questions about Creativity in La edad del pavo. En: Adams, J. (ed.) Mimetic Desire: Essays on Narcissism in German Literature from Romanticism to Post Modernism, pp.34-49. Columbia: Camden House.

" Koepke, W. (1991). Bildung and the Transformation of Society: Jean Paul's Titan and La edad del pavo. En: Hardin, J.(ed.). Reflection and Action, pp. 228-253. Columbia: South Carolina University Press.

"Kommerell, M. (1977). Jean Paul. Frankfurt/M: Vittorio Klostermann.

"Koval, M. (2018). Vocación y renuncia. La novela de formación alemana entre la Ilustración y la Primera Guerra Mundial. Buenos Aires: EFFL.

"Moretti, F. (1987). The Way of the World. The Bildungsroman in European Culture. Londres: Verso.

" Müller, G. (1968). "Gestaltung-Umgestaltung in Wilhelm Meisters Lehrjahren. Die Metamorphose der Menschen". En Morphologische Poetik. Gesammelte Aufsätze, pp. 419-510. Darmstadt: Wissenschaftliche Buchgesellschaft.

"Pascal, R. (1968). Johann Wolfgang Goethe- Wilhelm Meister. En The German Novel, pp. 3-29 Manchester: Manchester University Press.

"Schlegel, F. (2012). Conversación sobre la poesía. En: Lacoue Labarthe, P.; Nancy, J. L. 
Jean Paul, lector de Goethe: La edad...

(eds.). El absoluto literario: Teoría de la literatura del romanticismo alemán. Trad. de: C. González y L. Carugati. pp. 358- 421. Buenos Aires: Eterna Cadencia.

"Swales, M. (1978). The German Bildungsroman from Wieland to Hesse. Nueva Jersey: Princeton University Press.

"Vedda, M. (2015). Leer a Goethe. Buenos Aires: Quadrata. 